\title{
Referral patterns to outpatient child and adolescent mental health services and factors associated with referrals being rejected. A cross-sectional observational study
}

Anna Sofie Hansen ${ }^{1,2^{*}}$, Cecilie Haugaard Christoffersen ${ }^{1}$, Gry Kjaersdam Telléus ${ }^{1,3}$ and Marlene Briciet Lauritsen ${ }^{1,2}$

\begin{abstract}
Background: Outpatient child and adolescent mental health services (CAMHS) are faced with the challenge of balancing increasing demands with limited resources. An additional challenge is high rejection rates of referrals which causes frustration for referring agents and families. In order to effectively plan and allocate available resources within CAMHS there is a need for up-to-date knowledge on referral patterns and factors associated with rejection of referrals.

Methods: In this cross-sectional observational study we did a retrospective review of all referrals $(n=1825)$ for children (0-18) referred for assessment at the outpatient CAMHS of the North Denmark Region in 2018.

Results: The most common referral reasons to CAMHS were attention deficit disorder (ADHD/ADD) (27.9\%), autism spectrum disorder (22.4\%), affective disorders (14.0\%) and anxiety disorders (11.6\%). The majority of referrals came from general practitioners, but for neurodevelopmental disorders educational psychologists were the primary referral source. Re-referrals constituted more than a third of all referrals (35.9\%). Children in care were overrepresented in this clinical sample and had an increased risk (Adj. OR 2.54) of having their referrals rejected by CAMHS. Referrals from general practitioners were also associated with an increased risk of rejection (Adj. OR 3.29).

Conclusions: A high proportion of children with mental disorders have a repeated need for assessment by CAMHS. There is a need for future research on predictors of re-referral to outpatient services to identify potential targets for reducing re-referral rates as well as research on how to optimize service provision for children with a repeated need for assessment. General practitioners are the main gatekeepers to CAMHS and research on interventions to improve the referral process should be aimed towards general practitioners.
\end{abstract}

Keywords: Referral pattern, Referral decision, Rejection, Service use, Child psychiatry, Adolescent psychiatry

\footnotetext{
* Correspondence: anna.hansen@rn.dk

'Aalborg University Hospital, Psychiatry, Mølleparkvej 10, 9000 Aalborg, Denmark

${ }^{2}$ Department of Clinical Medicine, Aalborg University, Sdr. Skovvej 15, 9000

Aalborg, Denmark

Full list of author information is available at the end of the article
}

(c) The Author(s). 2021 Open Access This article is licensed under a Creative Commons Attribution 4.0 International License, which permits use, sharing, adaptation, distribution and reproduction in any medium or format, as long as you give appropriate credit to the original author(s) and the source, provide a link to the Creative Commons licence, and indicate if changes were made. The images or other third party material in this article are included in the article's Creative Commons licence, unless indicated otherwise in a credit line to the material. If material is not included in the article's Creative Commons licence and your intended use is not permitted by statutory regulation or exceeds the permitted use, you will need to obtain permission directly from the copyright holder. To view a copy of this licence, visit http://creativecommons.org/licenses/by/4.0/. The Creative Commons Public Domain Dedication waiver (http://creativecommons.org/publicdomain/zero/1.0/) applies to the data made available in this article, unless otherwise stated in a credit line to the data. 


\section{Introduction}

Childhood mental disorders are common with a worldwide prevalence of $13.4 \%$ [1] and more than $50 \%$ of lifetime mental disorders have their onset before the age of $18[2,3]$. Childhood mental disorders largely influence children and young people's (CYP) health, education and well-being $[4,5]$ and have a high economic impact on society $[6,7]$. In the past decades there has been a steep increase in referral rates to outpatient child and adolescent mental health services (CAMHS) $[4,8,9]$ but research continues to document large unmet needs for CAMHS among CYP with mental disorders [9-11]. This leaves CAMHS in the dilemma of balancing existing resources with increasing demands as investments in CAMHS do not match the resources needed to provide services to all CYP in need $[12,13]$. In order to effectively plan and allocate available resources within $\mathrm{CAMH}$ $\mathrm{S}$ we need current knowledge on referral patterns, but international research within this field is scarce [14].

Child mental health services are often organized in a stepped care approach [15] with multi-agency collaborations across social services, education and healthcare. The aim is to ensure that milder mental health problems are treated in primary care settings (general practitioners, education and social services) and only children with moderate to severe mental disorders are be referred to CAMHS [16, 17].

The Danish model of stepped care for CYP with mental disorders is outlined in Fig. 1 and is very similar to the tier model in the UK [18]. General practitioners (GPs) are the main gatekeepers to CAMHS [14, 18-21] in most European countries, but educational services also play an important role in the referral process [18, 21-23]. This potentially makes the referral process more complex. Professionals from primary settings, like GPs, and parents have expressed frustration with high rejection rates by CAMHS [24, 25] and studies have documented that GPs are uncertain about referral criteria to CAMHS [26]. In Denmark the rejection rate for referrals by CAMHS has been stable at around $20-25 \%$ for the last decade [27], which is in line with findings from other Scandinavian countries and the UK [20, 27, 28]. Despite the important role of the referral process in care pathways and the identified problems associated with referrals to outpatient services there has been very little research on interventions to improve the referral process [29]. In order to tailor interventions aimed at minimizing rejection rates, we first need to identify factors associated with increased risk of rejection. Very few studies have done so for CAMHS. Studies from the UK found increased odds of rejection for referrals from GPs [20] and teachers [18] as well as for referrals form emotional and behavioral difficulties [18]. Further research on who is rejected and why is still needed.
The aim of this study is to contribute knowledge on current referral pattern to outpatient CAMHS and investigate what characteristics are associated with rejection of referrals.

\section{Methods and materials}

The study was a cross-sectional observational study. A retrospective systematic review was conducted of referral letters to outpatient CAMHS. The study was an exploratory study, with no hypothesis formulated in advance.

All referral letters for assessment of CYP under 18 years received at the CAMHS of the North Denmark Region from January-December 2018 were included in the study. Referrals with the purpose of treatment of an already diagnosed mental disorder were excluded from the study, as were referrals where it was not possible to determine if the purpose of the referral was assessment or treatment.

The study was conducted at the only CAMHS in the North Denmark Region. The CAMHS provides multidisciplinary specialist mental health services. The catchment area for the center covers both urban and rural areas with approximately 114,000 inhabitants between 0 and 18 years of age [30]. At the study center $96 \%$ of accepted referrals were seen for a first appointment within 30 days [31].

\section{Procedure}

Referral information was extracted from the referral letters using a bespoke form developed for this study. The referral letters were reviewed by three graduate level psychology students after training by the first author (ASH), who is a 5 th year child and adolescent psychiatric trainee. The graduate students could also consult with ASH when reviewing the referral letters.

\section{Variables}

Information on referral decision, placement in care and any previous contacts to CAMHS in the North Denmark Region was obtained from the electronic records. In addition, referral letters were checked for information about previous assessments for a mental disorder conducted outside the study center. Sociodemographic characteristics included age, sex and placement in care.

Referral source was categorized into four categories: GPs, other medical doctor (private practicing specialist or hospital-based medical doctor), educational psychologist or case worker from social services.

Primary referral diagnosis was assigned according to ICD-10 [32] by a specialist in child and adolescent psychiatry to all referrals that were accepted to the CAMHS. If the referral was rejected, the referral diagnosis stated on the referral letter by the referring agent was taken as the primary referral diagnosis. In case of 


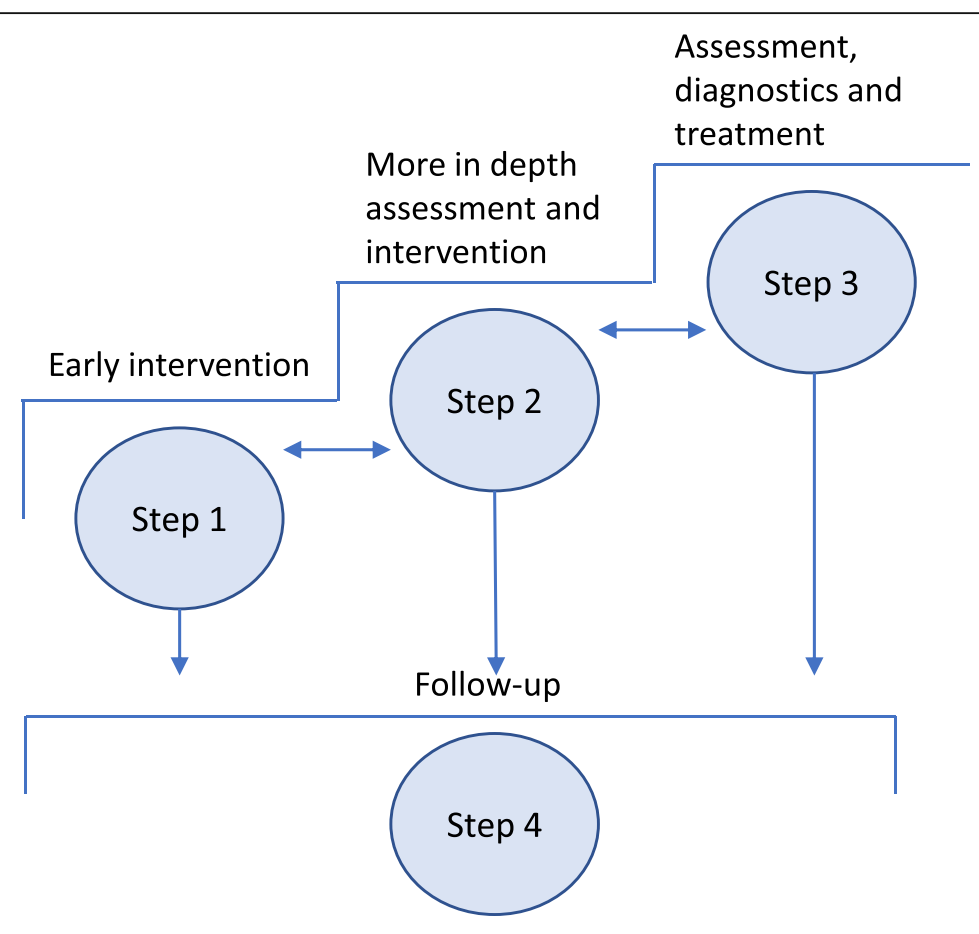

\begin{tabular}{|l|l|}
\hline Step 1 & $\begin{array}{l}\text { Professionals involved } \\
\text { Professionals working in universal services (such as GPs, } \\
\text { health visitors, teachers and youth workers), who are not } \\
\text { necessarily mental health specialists. } \\
\text { They offer general advice and treatment for less severe } \\
\text { problems, promote mental health, aid early identification of } \\
\text { problems and refer to more specialist services. }\end{array}$ \\
\hline Step 2 & $\begin{array}{l}\text { Specialist working in the community and primary } \\
\text { care settings such as primary mental health workers, } \\
\text { allied health professionals, psychologists and } \\
\text { pediatricians. } \\
\text { They offer consultations to families and other } \\
\text { practitioners, outreach to identify severe/complex } \\
\text { needs and assessment and training to professionals } \\
\text { working on Step 1. }\end{array}$ \\
\hline Step 3 & $\begin{array}{l}\text { Services provided by multi-diciplinary childand } \\
\text { adolescent psychiatric clinics or private practicing } \\
\text { child and adolecent psychiatrists. } \\
\text { They offer a specialized service for those with more } \\
\text { severe, complex and persistent disorders. }\end{array}$ \\
\hline Step 4 & $\begin{array}{l}\text { Continuous follow-up of interventions from Step 1-3. } \\
\text { soling }\end{array}$ \\
\hline
\end{tabular}

Fig. 1 Danish model of stepped care for children with mental disorders. Model for stepped-care based on the model in the Danish Health Authorities disease management program for mental disorders in children and adolescents [17] 
multiple referral diagnoses on a rejected referral, the primary referral diagnosis was decided by the first author (ASH) based on the referral letter. Primary referral diagnoses were divided into broader diagnostic categories as seen in Table 1. Specified referral diagnosis, that constituted less than $2.5 \%$ of the referrals were grouped together as "other". These included psychoses, tic disorders, attachment disorder, conduct disorder and personality disorder.

Previous support/interventions were documented based on information from the referral letters. Previous support/interventions were subdivided into support/interventions provided in school, psychosocial support/ interventions provided outside of school and support/interventions provided by healthcare professionals. Allied health professionals included physiotherapists, occupational therapists, speech therapists, health visitors and dieticians.

Descriptions of cognitive level of functioning were also extracted from the referral letter, as was impact of mental health problems on schooling and information about self-harm or suicidal ideations.

Impact on schooling included academic problems, absence from school on some days and complete school absence for the CYP and was included as a proxy variable for functional impairment caused by the CYP's mental health problems.

\section{Statistical analysis}

Descriptive statistics are reported as N (\%) for all categorical variables and as median (interquartile range (IQR)) for referral age. For categorical variables, the Chisquared test was applied. ANOVA was used for continuous variables. Post-hoc pairwise comparisons were made to investigate for differences in referrals for the four most common primary referral diagnoses.

Logistic regression was used to examine factors associated with a referral being rejected. To check for reliability of the data extraction 20 randomly selected referral letters reviewed by each of the graduate students were also reviewed by ASH. Reliability of the data extraction from the referral letters was calculated using an average of Cohen's Kappa for all extracted variables comparing each rater to ASH.

The level of statistical significance was set at 5\% for all analyses. All statistical analyses were executed using Stata Statistical Software: Release 15. College Station, TX: StataCorp LLC.

Table 1 Characteristics of the sample

\begin{tabular}{|c|c|c|c|c|c|c|}
\hline \multicolumn{2}{|c|}{ Total sample } & \multicolumn{2}{|c|}{ Accepted } & \multicolumn{2}{|c|}{ Rejected } & \multirow[t]{2}{*}{$P$-value } \\
\hline $\mathrm{N}$ & $\%$ & $\mathrm{~N}$ & $\%$ & $\mathrm{~N}$ & $\%$ & \\
\hline 1825 & 100 & 1363 & 74.7 & 462 & 25.3 & \\
\hline
\end{tabular}

Sociodemographic characteristics

Boys
Median age (IQR)

Placement in care

Previous contact for mental health problems

Previously referred, but referral rejected

Previously assessed for a mental disorder

\section{Referral source}

General practitioner

Other medical doctor

Educational psychologist

Case worker social services

989
13.5
135

Primary referral diagnosis

Affective disorder
Anxiety disorder
Reactions to severe stress and adjustment disorders
Eating disorder
Autism spectrum disorder
Attention Deficit disorder (ADHD/ADD)
Other
Unspecified

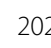

452

(11.1)

(24.8)

(54.2)

$(9.5-16.0)$

745

\section{(54.7)}

(9.6-16.0)

(5.8)

244

244

(52.8)

0.49

(7.4)

79

983

173

(53.9)

(9.5)

568

(31.1)

101

(5.5)

255

212

(14.0)

(11.6)

98

(5.4)

90

(4.9)

409

509

(22.4)

(27.9)

168

(9.2)

84

\begin{tabular}{lllll}
144 & $(10.6)$ & 58 & $(12.6)$ & 0.24 \\
357 & $(26.2)$ & 95 & $(20.6)$ & $\mathbf{0 . 0 2}$ \\
& & & & \\
638 & $(46.8)$ & 345 & $(74.7)$ & $<\mathbf{0 . 0 0 1}$ \\
141 & $(10.3)$ & 32 & $(6.9)$ & $\mathbf{0 . 0 4}$ \\
506 & $(37.1)$ & 62 & $(13.4)$ & $<\mathbf{0 . 0 0 1}$ \\
78 & $(5.7)$ & 23 & $(5.0)$ & 0.56 \\
& & & & \\
213 & $(15.6)$ & 42 & $(9.1)$ & $<\mathbf{0 . 0 0 1}$ \\
149 & $(10.9)$ & 63 & $(13.6)$ & 0.12 \\
89 & $(6.5)$ & 9 & $(2.0)$ & $<\mathbf{0 . 0 0 1}$ \\
70 & $(5.1)$ & 20 & $(4.3)$ & 0.49 \\
351 & $(25.8)$ & 58 & $(12.6)$ & $<\mathbf{0 . 0 0 1}$ \\
385 & $(28.3)$ & 124 & $(26.8)$ & 0.56 \\
101 & $(7.4)$ & 67 & $(14.5)$ & $<\mathbf{0 . 0 0 1}$ \\
5 & $(0.4)$ & 79 & $(17.1)$ & $<\mathbf{0 . 0 0 1}$ \\
\hline
\end{tabular}




\section{Results}

Overall reliability for the data extraction was moderate to strong with an average of kappa values for all computed variables between $0.77-0.81$.

\section{Sample}

In 2018, CAMHS in the North Region of Denmark received 2237 referral letters to outpatient services (Fig. 2). Of these four referral letters could not be retrieved, 370 were referred for treatment of a previously diagnosed mental disorder, and for 38 referral letters it was not possible to determine if the referral was for assessment or treatment of an existing disorder. Thus, 1825 referrals were included in the study. Of these $74.7 \%(n=1363)$ were accepted for assessment and $25.3 \%(n=462)$ were rejected.

\section{Referral pattern}

As seen in Table 1, just over half (54.2\%) of the referrals were for boys. The median referral age was 13.5 years (IQR 9.5-16.0). Referred girls were significantly older (median 14.8, IQR 12.2-16.5) than the referred boys (median age 11.5, IQR 8.1-15.0) $(p<0.001)$. CYP placed in care constituted $7.4 \%$ of the sample. More than a third of the referrals were re-referrals (35.9\%), and $24.8 \%$ had previously been assessed for a mental disorder. The majority of the referrals came from GPs (53.9\%), followed by educational psychologists (31.1\%). The four primary referral diagnoses were attention deficit disorder (ADHD/ADD, 27.9\%), followed by autism spectrum disorder (ASD, 22.4\%), affective disorder (14.0\%), and anxiety disorder (11.6\%).
Differences in referrals for the four most common primary referral diagnoses

As seen in Table 2 there were significant sociodemographic differences between the referrals for the four most common primary referral diagnoses. CYP referred for ADHD/ADD were statistically significantly more often placed in care compared to CYP referred for ASD or anxiety disorders $(p=0.02)$ (Table 2$)$. Medical doctors (GP or other) referred $95.3 \%$ of all referrals for affective disorders and $88.3 \%$ of referrals for anxiety disorders, whereas educational psychologists were the primary referral source for referrals for ASD (58.4\%) and ADHD/ ADD (47.7\%).

When looking at previous support/interventions described in the referral letter, there were also significant differences (Table 2). Almost all CYP referred for assessment of ASD (94.1\%) and ADHD/ADD (89.8\%) had received some form of support/intervention prior to referral, which was statistically significantly $(p<0.001)$ more frequently than for CYP referred for anxiety disorders $(75.0 \%)$ and affective disorders (67.8\%). The type of support/intervention received prior to referral also differed according to primary referral diagnosis. Descriptions of support/interventions in school were present in less than $30.0 \%$ of referrals for affective disorders, whereas school interventions were mentioned in $87.0 \%$ of referrals for ASD. More than a fifth of the children referred for assessment for ASD or ADHD/ADD were in full time special needs education programs at the time of referral, compared to only one in 14 of children and adolescents referred for affective disorders. For referrals for both affective disorders and anxiety disorders, psychosocial interventions were mentioned in almost half of

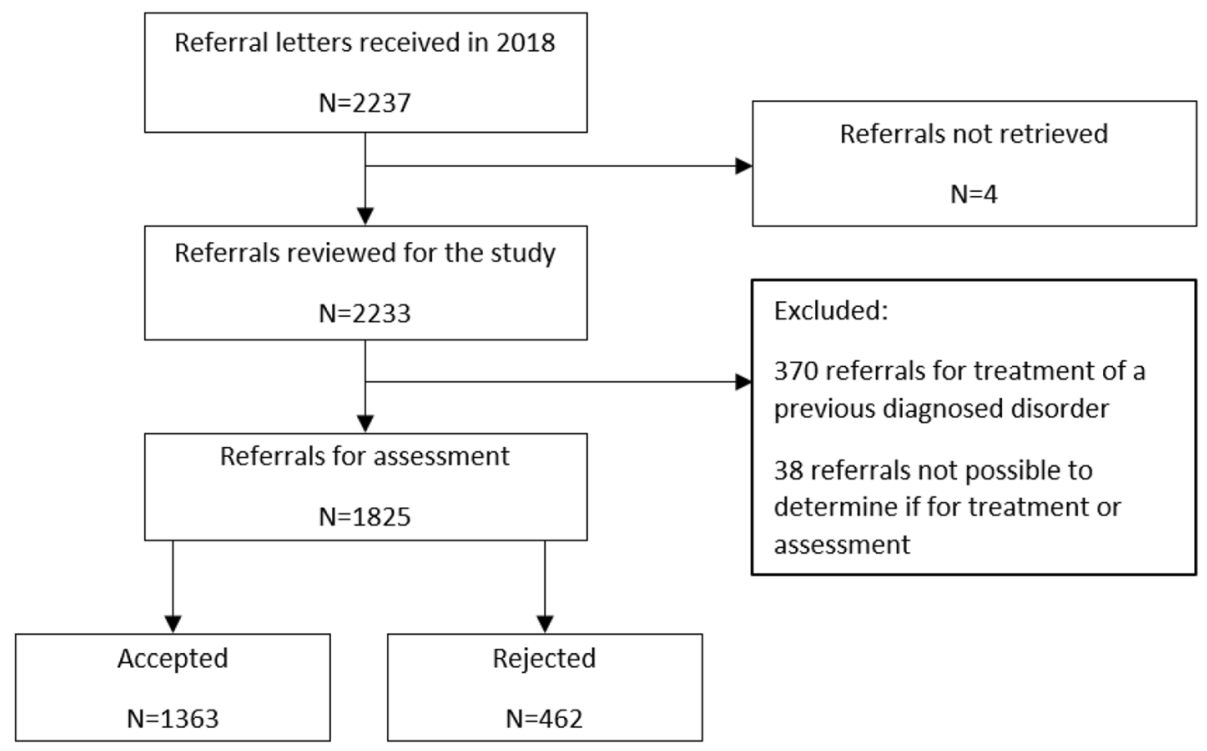

Fig. 2 Study sample 
Table 2 Content of referral letters for the four most common primary referral diagnoses

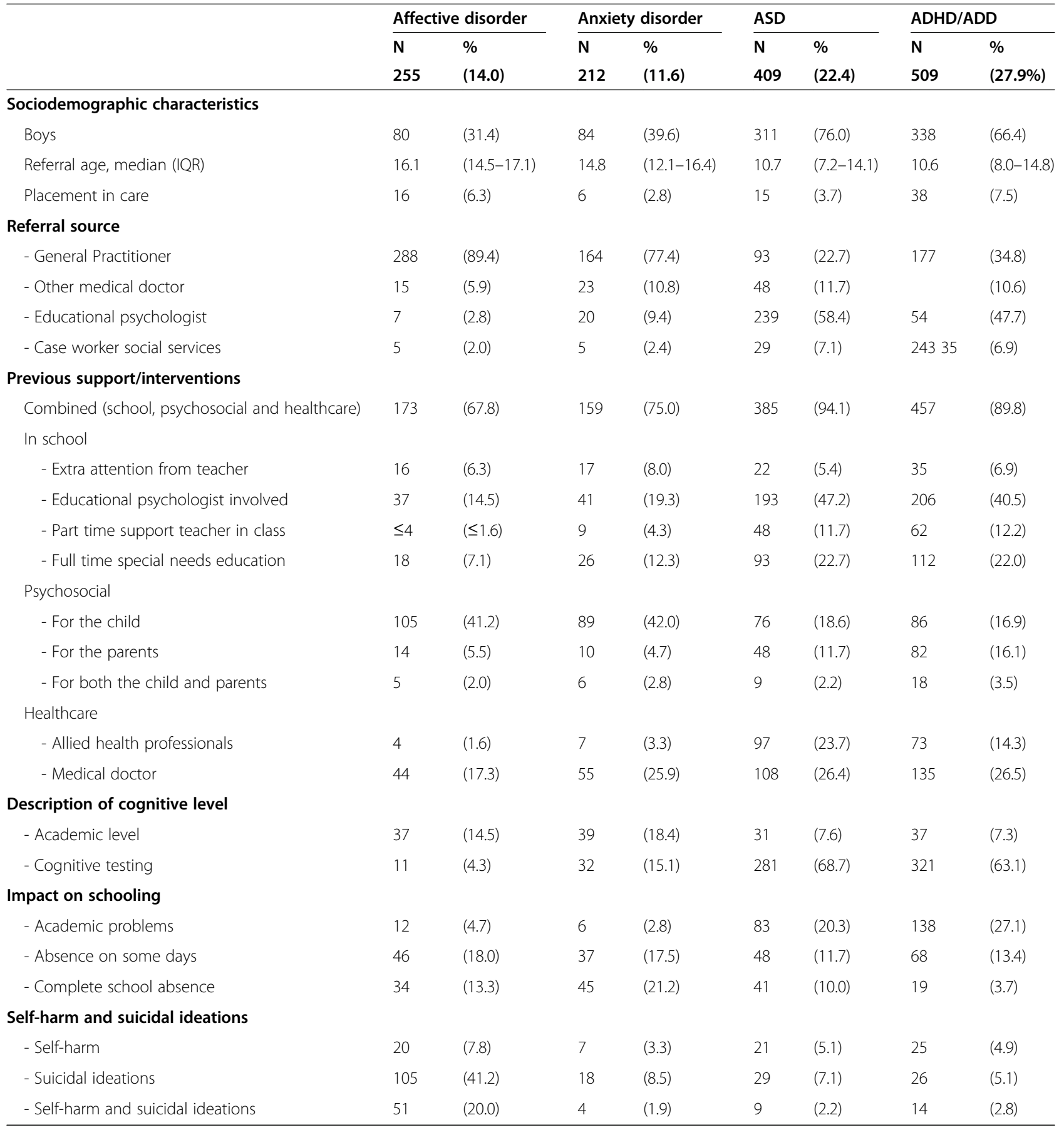

ASD Autism Spectrum Disorders, ADHD/ADD Attention Deficit Hyperactivity Disorder/Attention Deficit Disorder

the referral letters, with the intervention most commonly aimed at the child $(41.2 \%$ for affective disorders and $42.0 \%$ for anxiety disorders). Description of previous psychosocial interventions were statistically less common in referrals for ASD and ADHD/ADD $(p<0.001)$ compared to referrals for affective disorders and anxiety disorders, while psychosocial interventions aimed at the parents were statistically significantly more common in referrals for ASD and ADHD/ADD $(p<0.001)$. Descriptions of previous interventions by allied health professionals were most common in referrals for autism (23.7\%). In $21.2 \%$ of referrals for anxiety disorders the referral letter mentioned that the CYP was not currently in school which was only the case in $10.0 \%$ of referrals for ASD and $3.7 \%$ for ADHD. 
Factors associated with rejection of referral from CAMHS Table 3 shows the association between different factors and the decision by CAMHS to reject a referral. The adjusted logistic regression model was adjusted for age, sex, placement in care, previous contacts for mental health problems, referral source, primary referral diagnosis, previous support/interventions (in school, psychosocial, healthcare), description of cognitive level, impact on schooling and self-harm/suicidal ideations. We found no association between age or sex and rejection of referral (data not shown).

Referrals for CYP in care had a statistically significant increased risk of being rejected (Adj. OR 2.54, 95\%CI 1.61-4.00). Referrals from GPs (Adj. OR 3.29, 95\%CI 2.35-4.62) and referrals with "other" (Adj. OR 1.76, $95 \%$ CI $1.22-2.54$ ) as the primary referral diagnosis also had an increased risk of being rejected. Previous assessment for a mental disorder was associated with decreased risk of rejection (Adj OR 0.71, 95\%CI 0.52-0.98) as was being referred by an educational psychologist (Adj. OR 0.30, 95\%CI 0.21-0.45). Several primary referral diagnoses were associated with decreased risk of rejection (Table 3).

Part time support teacher in the class (Adj. OR 0.53, 95\%CI $0.30-0.95)$ and intervention by health professionals (Adj. OR 0.60, 95\%CI 0.37-0.99 for allied health professionals and Adj. OR 0.41, 95\%CI 0.18-0.89 for medical doctor) were the only previous support/interventions associated with decreased risk of rejection in the adjusted regression analyses. Description of previous cognitive testing was also associated with decreased risk of rejection (Adj. OR 0.34, 95\%CI 0.23-0.50).

\section{Discussion}

In this explorative cross-sectional study, we investigated referral patterns to outpatient CAMHS, and factors associated with referrals being rejected from CAMHS.

The sex and age distribution found in our sample is similar to that found in other European clinical samples $[14,18,21]$. In the following key findings from the study will be discussed.

\section{CYP placed in care}

CYP placed in care were overrepresented in this study constituting $7.4 \%$ of referrals compared to only $1 \%$ in the background population in Denmark [33]. This is in line with previous findings by Larsen et al. who also reported high service use for this group, but also large unmet needs [34]. Another key finding was that CYP placed in care had a 2.54 increased risk of their referral being rejected compared to CYP living at home. Previous studies have documented that the prevalence for mental disorders in CYP placed in care is almost fourfold greater than in the general population [35, 36]. A systematic review of outcomes for CYP in care in the Nordic countries found that as young adults, CYP placed in care, had an increased risk of mental health problems, suicidal behavior and higher mortality in young adulthood compared to the general population [37]. Given this knowledge it is worrisome, that being placed in care is associated with increased risk of being rejected by CAMHS.

\section{Re-referrals}

More than a third of referrals to CAMHS were rereferrals. This is comparable to previous findings from the UK [20] and Canada [38, 39]. Despite high re-referral rates, there is a paucity of research on predicters of re-referral to outpatient CAMHS [40]. There are several possible explanations for the high proportion of re-referrals. The nature of childhood mental disorders is that they are often persistent [10, 38 ] and recurrence rates for disorders such as depression and anxiety disorders are high [41]. In addition heterogeneity in psychopathological development [42] can result in a need for renewed assessment by CAMHS. Re-referrals as a result of the nature of childhood mental disorders are probably not preventable. However, there could be other preventable contributing factors. Co-morbidity rates for childhood mental disorders are high [43] and although comorbid conditions might not develop until after initial assessment, there is also the possibility that co-morbidity is missed at initial assessment. Structured diagnostic interviews have been shown to increase the likelihood of clinicians diagnosing comorbid disorders [44-46]. However, structured diagnostic interviews are often not used in routine clinical assessment [47-49]. This is relevant because overlooked disorders could have a negative effect on the treatment outcome for the child [49]. Development of co-morbid disorders postassessment could be a result of insufficient service provision in primary settings following diagnosis of the primary disorder. Studies from in-patient setting have found an association between lower levels of aftercare [50] and delay in provision of aftercare services [51] and increased risk of re-admission. There is a need for more research on predictors of re-referral to outpatient CAMHS to identify targets for improvement of service provision for CYP with mental disorders. Regardless of the explanation, the high referral rates call for research on how to optimize services for children with a repeated need for referral to CAMHS [39]. With the knowledge of high comorbidity rates, it is positive that we found that previously having been assessed for a psychiatric diagnosis is associated with a decreased risk for a referral being rejected. 
Table 3 Logistic regression model: factors associated with rejection of referral from CAMHS

\begin{tabular}{|c|c|c|c|c|}
\hline & \multicolumn{2}{|c|}{ Rejected (unadjusted) } & \multicolumn{2}{|c|}{ Rejected (adjusted) $^{\mathrm{a}}$} \\
\hline & OR & $95 \% \mathrm{Cl}$ & OR & $95 \% \mathrm{Cl}$ \\
\hline \multicolumn{5}{|l|}{ Placement in care } \\
\hline - Lives with parents & Reference & & Reference & \\
\hline - Placed in foster care or residential home & 2.24 & $(1.56-3.21)$ & 2.54 & $(1.61-4.00)$ \\
\hline \multicolumn{5}{|l|}{ Previous contact for mental health problems } \\
\hline - First time referral & Reference & & Reference & \\
\hline - Previously rejected & 1.12 & $(0.81-1.57)$ & 1.23 & $(0.85-1.78)$ \\
\hline - Previously assessed & 0.74 & $(0.57-0.96)$ & 0.71 & $(0.52-0.98)$ \\
\hline \multicolumn{5}{|l|}{ Referral source } \\
\hline - General practitioner & 3.35 & $(2.65-4.24)$ & 3.29 & $(2.35-4.61)$ \\
\hline - Other medical doctor & 0.67 & $(0.45-0.99)$ & 0.64 & $(0.40-1.02)$ \\
\hline - Educational psychologist & 0.26 & $(0.20-0.35)$ & 0.30 & $(0.21-0.45)$ \\
\hline - Social worker & 0.86 & $(0.54-1.39)$ & 0.81 & $(0.48-1.38)$ \\
\hline \multicolumn{5}{|l|}{ Primary referral diagnosis } \\
\hline - Affective disorder & 0.54 & $(0.38-0.77)$ & 0.37 & $(0.25-0.55)$ \\
\hline - Anxiety disorder & 1.29 & $(0.94-1.76)$ & 1.00 & $(0.70-1.45)$ \\
\hline - Adjustment disorder & 0.28 & $(0.14-0.57)$ & 0.23 & $(0.11-0.46)$ \\
\hline - Eating disorder & 0.84 & $(0.50-1.39)$ & 0.52 & $(0.30-0.90)$ \\
\hline - Autism & 0.41 & $(0.31-0.56)$ & 0.54 & $(0.38-0.76)$ \\
\hline - ADHD/ADD & 0.93 & $(0.73-1.18)$ & 1.18 & $(0.90-1.55)$ \\
\hline - Other & 2.12 & $(1.52-2.94)$ & 1.76 & $(1.22-2.54)$ \\
\hline
\end{tabular}

\section{Previous support/interventions}

$$
\begin{aligned}
& \text { In school } \\
& \text { - No support } \\
& \text { - Extra attention from teacher } \\
& \text { - Educational psychologist involved } \\
& \text { - Part time support teacher in class } \\
& \text { - Full time special needs education program } \\
& \text { Psychosocial } \\
& \text { - No interventions } \\
& \text { - for the child } \\
& \text { - for the family/parents } \\
& \text { - for both the child and the family/parents } \\
& \text { Healthcare } \\
& \text { - No support } \\
& \text { - Allied health professionals } \\
& \text { - Medical doctor } \\
& \text { - Allied health professionals + medical doctor }
\end{aligned}
$$

Description of cognitive level of functioning

None

Cognitive testing

Impact on schooling

No description

Academic problems
Reference

0.66

0.53

0.32

0.50

Reference

0.61

0.69

0.79

Reference

0.48

0.67

0.31

Reference

0.31

Reference

0.49
$(0.47-0.80)$

(0.48-0.99)

$(0.41-1.53)$

(0.30-0.77)

(0.51-0.89)

(0.15-0.67)

(0.41-1.04)

$(0.41-0.68)$

$(0.20-0.54)$

$(0.36-0.68)$

(0.24-0.40)

$(0.35-0.69)$
Reference

$$
1.18
$$

0.96

0.53

0.86

(0.65-2.15)

(0.68-1.36)

(0.30-0.95)

(0.56-1.30)

Reference

0.83

(0.61-1.13)

0.98

(0.65-1.49)

1.56

(0.75-3.22)

Reference

0.60

(0.37-0.99)

0.41

(0.18-0.89)

0.70

(0.51-0.95)

Reference

0.34

$(0.23-0.50)$

Reference

0.81

(0.55-1.18) 
Table 3 Logistic regression model: factors associated with rejection of referral from CAMHS (Continued)

\begin{tabular}{|c|c|c|c|c|}
\hline & \multicolumn{2}{|c|}{ Rejected (unadjusted) } & \multicolumn{2}{|c|}{ Rejected (adjusted) ${ }^{a}$} \\
\hline & $\overline{\mathrm{OR}}$ & $95 \% \mathrm{Cl}$ & $\overline{O R}$ & $95 \% \mathrm{Cl}$ \\
\hline Absence on some days & 0.72 & $(0.52-0.98)$ & 0.90 & $(0.63-1.27)$ \\
\hline Complete school absence & 0.55 & $(0.37-0.82)$ & 0.85 & $(0.54-1.35)$ \\
\hline \multicolumn{5}{|l|}{ Self-harm and suicidal ideations } \\
\hline No description & Refer & & & \\
\hline Self-harm without suicidal ideations & 1.04 & $(0.66-1.62)$ & 0.83 & $(0.50-1.40)$ \\
\hline Suicidal ideations & 0.69 & $(0.49-0.98)$ & 0.80 & $(0.54-1.19)$ \\
\hline
\end{tabular}

${ }^{a}$ Adjusted for age, sex, placement in care, previous contacts for mental health problems, referral source, primary referral diagnosis, previous support/interventions, description of cognitive level, impact on schooling and self-harm/suicidal ideations

\section{Referral source}

Referral from a GP was associated with a three times higher risk of the referral being rejected. This is relevant as GPs were responsible for the majority of referrals. The finding is in line with a study by Hinrichs et al., but contrasts with findings by Smith et al. who found increased risk of rejection for referrals from teachers compared to GPs $[18,20]$. In Denmark teachers can not refer directly to CAMHS, so any referral from the educational system comes from educational psychologists. Teachers have limited training in child mental health [52], whereas educational psychologists have more indepth knowledge of child mental health problems. Results from this study, indicates that referrals from professionals with more specialized knowledge are more often accepted by CAMHS than referrals by GPs. This might be due to these professionals having more time and options for both assessment and interventions prior to referral to CAMHS in accordance with the stepped care policy. However, involvement of professionals at a higher level in the stepped-care model prior to referral to CAMHS also requires a referral and may delay necessary assessment by CAMHS. GPs have expressed frustration with frequent rejections by CAMHS and a lack of clarity about the organization of mental health services for CYP [24]. In a systematic review of barriers to managing CYP mental health problems in primary health care settings O'Brien et al., identified lack of knowledge, skills, tools, time and resources as barriers for GPs referring to CAMHS [53]. In addition, they identified a desire from GPs for feedback on referrals as well as clearer referral criteria [53]. There is a need for further research to investigate why the rejection rate for referrals from GPs is so much higher than for other referral sources. Further knowledge on whether the higher rejection rates are due to inappropriate referrals of CYP to CAMHS or lack of information in the referral due to lack of skills and tools for correctly describing symptoms of mental disorders in CYP is needed. In case missing information is the primary problem, the use of web-based diagnostic interviews like the Development and Well-being Assessment (DAWBA) [54] might be a useful tool.

\section{Primary referral diagnosis}

Referrals for affective disorder, reactions to severe stress and adjustment disorders and eating disorders were all associated with decreased risk of being rejected. It may be that these disorders all have a clearer onset of symptoms, with a distinctive change in the CYP's emotional state and/or behavior making them easier to identify as psychiatric symptoms. In addition, there could be a more acute need for treatment, where it is not possible to await the potential effect of interventions in primary settings. It is less clear why referrals for ASD are associated with decreased risk of rejection, when ADHD is not. Possibly the symptomatology of ASD, in contrast with that of ADHD/ADD, is more clearly distinguishable from symptoms of conduct disorders and learning disabilities, which in Denmark are primarily treated within educational and social services. Another explanation might be that children with ASD are perceived to be more in need of an assessment by CAMHS to access necessary services from other sectors.

\section{Previous support/interventions}

We found that the majority of CYP referred to CAMHS had received support/intervention prior to referral, which is in line with the stepped care model for child mental health services [16, 17]. However, a surprising finding from this study was that descriptions of most previous support/interventions in schools and all psychosocial support/interventions were not associated with a reduced risk of the referral being rejected. This finding might be due to a larger emphasis by CAMHS on psychopathology, i.e. if there are clear descriptions of psychiatric symptoms matching a moderate to severe mental disorder, than on whether interventions in primary settings have been attempted prior to referral. The same explanation might apply to why we also found no association between description in the referral letter of 
impact on schooling (i.e. academic problems or absence) or self-harm and the risk of rejection.

\section{Strengths and limitations}

To our knowledge this is the largest study to date investigating factors associated with rejection of referrals to CAMHS. The systematic review of the content of the referral letters is a strength compared to previous studies of referral patterns.

However, there are also some limitations to the study that should be mentioned. The study was carried out at a single CAMHS and the results might not be representative of other CAMHS. The primary referral diagnoses are not verified referral diagnoses and other countries might have different ways of classifying referral reasons to CAMHS making it hard to make direct comparisons across studies. We were not able to check if previous interventions were omitted from the referral letter which means the results regarding previous support/interventions could be underestimating the proportion of referred CYP who did receive support prior to referral. However, the results from this study with regards to the percentages of referred CYP with different referral diagnoses in full time special educational needs programs are in accordance with previously published national reports from Denmark [55].

\section{Conclusion}

GPs are the main gatekeepers to CAMHS, but educational services play an important role in referring children for neurodevelopmental disorders. Most CYP referred to CAMHS have received support/interventions from other services prior to referral in accordance with stepped care models. There is a need for further research to determine if the higher rejection rates for referrals from GPs are due to incorrect referrals for children not in need of CAMHS or due to missing information in the referrals. In either case, the findings indicate that there is a need to increase the knowledge of child mental disorders and child mental health services among GPs. Further research is also needed to shed light on why placement in care is associated with increased risk of rejection of referrals to CAMHS, as this is a vulnerable group with very high prevalence of mental disorders.

\footnotetext{
Abbreviations

CAMHS: Child and adolescent mental health service; ADHD/ADD: Attention deficit hyperactivity disorder/Attention deficit disorder; ASD: Autism spectrum disorder; CYP: Children and young people; GP: General practitioner; ICD-10: International classification of diseases version 10; IQR: Interquartile range; ANOVA: Analysis of variance; UK: United Kingdom;

DAWBA: Development and Well-Being Assessment
}

\section{Acknowledgements}

We would like to thank Line Hedegård Bredahl, Rasmus Hougaard Pedersen and Heidi Hattmann Hjortshøj for invaluable assistance with data collection.

\section{Authors' contributions}

ASH, GKT and MBL developed the study concept. ASH and CHC conducted data collection. ASH had full access to all collected data and performed data analysis and interpretation under the supervision of GKT and MBL. ASH and $\mathrm{CHC}$ drafted the manuscript and GKT and MBL provided critical revisions. All authors read and approved the final manuscript.

\section{Funding \\ This study was funded by TrygFonden, Aase og Ejner Danielsens Fond, AP Møller Lægefonden, Fru C. Hermansens Mindelegat and Helsefonden.}

Availability of data and materials

Data is available upon reasonable request to the corresponding author.

\section{Declarations}

\section{Ethics approval and consent to participate}

Permission to obtain access to data relevant to the study from the medical records was obtained from The Danish Patient Safety Authority (ref-number 3-3013-2794/1) and thus according to Danish legislation the requirement for informed consent for the review of information from the medical records was waived. Access to the medical records was granted by CAMHS in the North Denmark Region. Because the study did not include an intervention or collection of biological material according to Danish regulations, the study did not require further approval by an Ethics committee. This was confirmed by the Ethics Committee of the North Denmark Region. The study was conducted in accordance with relevant guidelines and regulations and was reported to the Danish Data Protection Agency (ref-number 2019-58).

\section{Consent for publication}

NA

\section{Competing interests}

The authors have declared that they have no competing or potential conflicts of interest.

\section{Author details}

${ }^{1}$ Aalborg University Hospital, Psychiatry, Mølleparkvej 10, 9000 Aalborg, Denmark. ²Department of Clinical Medicine, Aalborg University, Sdr. Skovvej 15, 9000 Aalborg, Denmark. ${ }^{3}$ Psychology, Department of Communication and Psychology, Aalborg University, Rendsburggade 14, 9000 Aalborg, Denmark.

Received: 26 January 2021 Accepted: 1 October 2021

Published online: 08 October 2021

\section{References}

1. Polanczyk GV, Salum GA, Sugaya LS, Caye A, Rohde LA. Annual research review: a meta-analysis of the worldwide prevalence of mental disorders in children and adolescents. J Child Psychol Psychiatry. 2015;56(3):345-65 Available from: http://www.ncbi.nlm.nih.gov/pubmed/25649325.

2. Kim-Cohen J, Caspi A, Moffitt TE, Harrington H, Milne BJ, Poulton R. Prior juvenile diagnoses in adults with mental disorder: developmental followback of a prospective-longitudinal cohort. Arch Gen Psychiatry. 2003;60(7): 709-17.

3. Kessler RC, Berglund P, Demler O, Jin R, Merikangas KR, Walters EE. Lifetime prevalence and age-of-onset distributions of DSM-IV disorders in the National Comorbidity Survey Replication. Arch Gen Psychiatry. 2005;62(6): 593-602. https://doi.org/10.1001/archpsyc.62.6.593.

4. Collishaw S. Annual research review: secular trends in child and adolescent mental health. J Child Psychol Psychiatry Allied Discip. 2015;56(3):370-93. https://doi.org/10.1111/jcpp.12372.

5. Segal L, Guy S, Leach M, Groves A, Turnbull C, Furber G. A needs-based workforce model to deliver tertiary-level community mental health care for distressed infants, children, and adolescents in South Australia: a mixedmethods study. Lancet Public Health. 2018;3(6):e296-303.

6. Fatori D, Salum G, Itria A, Pan P, Alvarenga P, Rohde LA, et al. The economic impact of subthreshold and clinical childhood mental disorders. J Ment Health. 2018;27(6):588-94. https://doi.org/10.1080/09638237.2018.1466041.

7. Doran CM, Kinchin I. A review of the economic impact of mental illness. Aust Health Rev. 2019;43(1):43-8. https://doi.org/10.1071/AH16115. 
8. Gyllenberg D, Marttila M, Sund R, Jokiranta-Olkoniemi E, Sourander A, Gissler $M$, et al. Temporal changes in the incidence of treated psychiatric and neurodevelopmental disorders during adolescence: an analysis of two national Finnish birth cohorts. Lancet Psychiatry. 2018;5(3):227-36.

9. Lempinen $L$, Luntamo $T$, Sourander $A$. Changes in mental health service use among 8-year-old children: a 24-year time-trend study. Eur Child Adolesc Psychiatry. 2019;28(4):521-30 Available from: https://doi.org/10.1007/s00787018-1218-9.

10. Ford T, Hamilton $\mathrm{H}$, Goodman R, Meltzer $\mathrm{H}$. Service contacts among the children participating in the British Child and Adolescent Mental Health Surveys. Child Adolesc Mental Health. 2005;10(1):2-9.

11. Kovess-Masfety V, Van Engelen J, Stone L, Otten R, Carta MG, Bitfoi A, et al. Unmet need for specialty mental health services among children across Europe. Psychiatr Serv. 2017;68(8):789-95. https://doi.org/10.1176/appi.ps.201 600409

12. World Psychiatric Association, WPA; World Health Organization W. Atlas: child and adolescent mental health resourcers. Global Concerns: Implications for the future. WHO Libr Cat. 2005.

13. Falissard B. Thinking the future of child and adolescent psychiatry: what are we talking about? Eur Child Adolesc Psychiatry. 2018;27(12):1519-21. https:// doi.org/10.1007/s00787-018-1252-7.

14. Reigstad B, Jørgensen K, Wichstrøm L. Changes in referrals to child and adolescent psychiatric services in Norway 1992-2001. Soc Psychiatry Psychiatr Epidemiol. 2004;39(10):818-27.

15. Von Korff M, Tiemens B. Individualized stepped care of chronic illness. West J Med. 2000;172(2):133-7.

16. Kelvin RG. Capacity of tier $2 / 3$ CAMHS and service specification: a model to enable evidence based service development. Child Adolesc Mental Health. 2005;10(2):63-73. https://doi.org/10.1111/j.1475-3588.2005.00120.x.

17. Sundhedsstyrelsen. Forløbsprogram for børn og unge med angst og/eller depression. 2017. Available from: https://www.sst.dk/da/udgivelser/2017/ / media/E62CECC2AE9440818723CADE96438A7B.ashx.

18. Smith J, Kyle RG, Daniel B, Hubbard G. Patterns of referral and waiting times for specialist child and adolescent mental health services. Child Adolesc Mental Health. 2018;23(1):41-9. https://doi.org/10.1111/camh.12207.

19. Zwaanswijk M, Verhaak PFM, Bensing JM, Van der Ende J, Verhulst FC. Help seeking for emotional and behavioural problems in children and adolescents: a review of recent literature. Eur Child Adolesc Psychiatry. 2003; 12(4):153-61. https://doi.org/10.1007/s00787-003-0322-6.

20. Hinrichs S, Owens M, Dunn V, Goodyer I. General practitioner experience and perception of Child and Adolescent Mental Health Services (CAMHS) care pathways: a multimethod research study. BMJ Open. 2012;2(6):e001573.

21. Pedrini L, Sisti D, Tiberti A, Preti A, Fabiani M, Ferraresi L, et al. Reasons and pathways of first-time consultations at child and adolescent mental health services in Italy: an observational study. Child Adolesc Psychiatry Ment Health. 2015;9:-29.

22. Farmer EMZ, Burns BJ, Phillips SD, Angold A, Costello EJ. Pathways into and through mental health services for children and adolescents. Psychiatr Serv. 2003;54(1):60-6.

23. Zwaanswijk M, Van Der Ende J, Verhaak PFM, Bensing JM, Verhulst FC. Helpseeking for child psychopathology: pathways to informal and professional services in the Netherlands. J Am Acad Child Adolesc Psychiatry. 2005 44(12):1292-300. https://doi.org/10.1097/01.chi.0000181038.98712.c6.

24. Roberts JH, Crosland A, Fulton J. "I think this is maybe our Achilles heel..." exploring GPs' responses to young people presenting with emotional distress in general practice: a qualitative study. BMJ Open. 2013;3(9): e002927.

25. Crouch L, Reardon T, Farrington A, Glover F, Creswell C. "Just keep pushing": Parents' experiences of accessing child and adolescent mental health services for child anxiety problems. Child Care Health Dev. 2019;45(4):491-9.

26. Lambert AK, Doherty AJ, Wilson N, Chauhan U, Mahadevan D. GP perceptions of community-based children's mental health services in Pennine Lancashire: a qualitative study. BJGP Open. 2020;4(4). https://doi. org/10.3399/bjgpopen20X101075.

27. Rambøll Management and Center for Kvalitetsudvikling RM. Henvisningsprojektet i børne- og ungdomspsykiatrien (in Danish)- ISBN: 978-87-7601-255-7. 2008. Available from: https://sum.dk/Aktuelt/Publika tioner/ /media/Filer-Publikationer_i_pdf/2008/Henvisningsprojektet.ashx.

28. Weisser $\mathrm{KH}$, Diseth $\mathrm{TH}$, Boye B, Faerden A, Ekeberg $\varnothing$. Examining the organization and quality of the psychiatric consultative service in Norway. Nord J Psychiatry. 2019;73(1):9-15.
29. Akbari A, Mayhew A, Al-Alawi MA, Grimshaw J, Winkens R, Glidewell E, et al. Interventions to improve outpatient referrals from primary care to secondary care. Cochrane Database Syst Rev. 2008;2008(4):CD005471. https://doi.org/10.1002/14651858.CD005471.pub2.

30. Danmarks Statistik. Statistikbanken (In Danish). 2018. [cited 2020 Nov 30]. Available from: https://www.statistikbanken.dk/10021

31. Danske Regioner. Opdaterede psykiatrital for 2018 (in Danish). 2019 Available from: https://www.regioner.dk/media/11429/opdaterede-psykia trital-for-2018.pdf

32. World Health Organization. ICD-10 : international statistical classification of diseases and related health problems : tenth revision. 2nd ed. Geneva PP Geneva: World Health Organization; 2004. Available from: https://apps.who. int/iris/handle/10665/42980

33. Danmarks Statistik. Støtte til børn og unge 2018. 2019. Available from: https://www.dst.dk/Site/Dst/Udgivelser/nyt/GetPdf.aspx?cid=28159.

34. Larsen M, Baste V, Bjørknes R, Myrvold T, Lehmann S. Services according to mental health needs for youth in foster care? - A multi-informant study. BMC Health Serv Res. 2018;18(1):634.

35. Bronsard $G$, Alessandrini $M$, Fond $G$, Loundou A, Auquier $P$, Tordjman S, et al. The prevalence of mental disorders among children and adolescents in the child welfare system a systematic review and meta-analysis. Med (United States). 2016;95(7):e2622.

36. Egelund T, Lausten M. Prevalence of mental health problems among children placed in out-of-home care in Denmark. Child Fam Soc Work. 2009; 14(2):156-65 Available from: https://doi.org/10.1111/j.1365-2206.2009.00620.

37. Kääriälä A, Hiilamo H. Children in out-of-home care as young adults: a systematic review of outcomes in the Nordic countries. Child Youth Serv Rev. 2017;79:107-14. https://doi.org/10.1016/j.childyouth.2017.05.030.

38. Reid G, Stewart SL, Zaric GS, Carter JR, Neufeld RWJ, Tobon Jl, et al. Defining episodes of care in children's mental health using administrative data. Adm Policy Ment Health Ment Health Serv Res. 2015;42(6):737-47. https://doi. org/10.1007/s10488-014-0609-6.

39. Reid GJ, Stewart SL, Barwick M, Carter J, Leschied A, Neufeld RWJ, et al. Predicting patterns of service utilization within children's mental health agencies. BMC Health Serv Res. 2019;19(1):993. https://doi.org/10.1186/s12 913-019-4842-2.

40. Sarmiento C. Predictors of re-accessing mental health services for children and adolescents. Western Ontario; 2017. Available from: https://ir.lib.uwo.ca/ etd/4660. Accessed 6 Aug 2021.

41. Schraeder KE, Reid GJ. Who should transition? Defining a target population of youth with depression and anxiety that will require adult mental health care. J Behav Health Serv Res. 2017;44(2):316-30. https://doi.org/10.1007/ s11414-015-9495-2.

42. Rutter M, Kim-Cohen J, Maughan B. Continuities and discontinuities in psychopathology between childhood and adult life. J Child Psychol Psychiatry Allied Discip. 2006:47(3-4):276-95.

43. Ollendick TH, Jarrett MA, Grills-Taquechel AE, Hovey LD, Wolff JC. Comorbidity as a predictor and moderator of treatment outcome in youth with anxiety, affective, attention deficit/hyperactivity disorder, and oppositional/conduct disorders. Clin Psychol Rev. 2008;28(8):1447-71.

44. Basco MR, Bostic JQ, Davies D, Rush AJ, Witte B, Hendrickse W, et al. Methods to improve diagnostic accuracy in a community mental health setting. Am J Psychiatry. 2000;157(10):1599-605. https://doi.org/10.1176/a ppi.ajp.157.10.1599.

45. Lauth $B$, Levy SRA, Júlíusdóttir G, Ferrari P, Pétursson H. Implementing the semi-structured interview Kiddie-SADS-PL into an in-patient adolescent clinical setting: Impact on frequency of diagnoses. Child Adolesc Psychiatry Ment Health. 2008;2(1):14.

46. Aebi M, Kuhn C, Metzke CW, Stringaris A, Goodman R, Steinhausen HC. The use of the development and well-being assessment (DAWBA) in clinical practice: a randomized trial. Eur Child Adolesc Psychiatry. 2012;21(10):559_ 67. https://doi.org/10.1007/s00787-012-0293-6.

47. Snell T, Knapp M, Healey A, Guglani S, Evans-Lacko S, Fernandez JL, et al. Economic impact of childhood psychiatric disorder on public sector services in Britain: estimates from national survey data. J Child Psychol Psychiatry Allied Discip. 2013;54(9):977-85.

48. Laursen FM. Diagnostic characteristics and outcomes of bipolar disorders in children and adolescents. Aalborg: Aalborg University; 2019.

49. Ford T, Last A, Henley W, Norman S, Guglani S, Kelesidi K, et al. Can standardized diagnostic assessment be a useful adjunct to clinical 
assessment in child mental health services? A randomized controlled trial of disclosure of the Development and Well-Being Assessment to practitioners. Soc Psychiatry Psychiatr Epidemiol. 2013;48(4):583-93.

50. Fontanella CA. The influence of clinical, treatment, and healthcare system characteristics on psychiatric readmission of adolescents. Am J Orthop. 2008;78(2):187-98. https://doi.org/10.1037/a0012557.

51. Yampolskaya S, Mowery D, Dollard N. Predictors for readmission into children's inpatient mental health treatment. Community Ment Health J. 2013;49(6):781-6. https://doi.org/10.1007/s10597-013-9592-8.

52. Yamaguchi S, Foo JC, Nishida A, Ogawa S, Togo F, Sasaki T. Mental health literacy programs for school teachers: a systematic review and narrative synthesis. Early Interv Psychiatry. 2020;14(1):14-25. https://doi.org/10.1111/ eip.12793.

53. O'Brien D, Harvey K, Howse J, Reardon T, Creswell C. Barriers to managing child and adolescent mental health problems: a systematic review of primary care practitioners' perceptions. Br J Gen Pract. 2016;66(651):e693707.

54. Goodman R, Ford T, Richards H, Gatward R, Meltzer H. The Development and Well-Being Assessment: Description and initial validation of an integrated assessement of child and adolescent psychopathology. J Child Psychol Psychiatry Allied Discip. 2000;41(5):645-55.

55. Kommunernes Landsforening. Børns diagnoser og skoletyper (Children's diagnoses and types of schooling) [in Danish]. 2018. Available from: https:// www.kl.dk/media/14395/ojyf-ezrxvgiuwyfuxvd.pdf.

\section{Publisher's Note}

Springer Nature remains neutral with regard to jurisdictional claims in published maps and institutional affiliations.

Ready to submit your research? Choose BMC and benefit from:

- fast, convenient online submission

- thorough peer review by experienced researchers in your field

- rapid publication on acceptance

- support for research data, including large and complex data types

- gold Open Access which fosters wider collaboration and increased citations

- maximum visibility for your research: over $100 \mathrm{M}$ website views per year

At $\mathrm{BMC}$, research is always in progress.

Learn more biomedcentral.com/submissions 